\title{
Involvement of regulatory volume decrease in the migration of nasopharyn- geal carcinoma cells
}

\author{
Jian Wen MAO ${ }^{1}$, Li Wei WANG ${ }^{2,3}$, Tim JACOB ${ }^{3}$, Xue Rong $\mathrm{SUN}^{2}$, Hui $\mathrm{LI}^{1}$, Lin Yan ZHU², Pan $\mathrm{LI}^{1}$, Ping ZHONG ${ }^{2}$, \\ Si Huai NIE ${ }^{2}$, Li Xin $\mathrm{CHEN}^{1,3, *}$ \\ ${ }^{1}$ Laboratory of Cell Biology, ${ }^{2}$ Laboratory of Physiology, Guangdong Medical College, Zhanjiang 524023, China \\ ${ }^{3}$ Cardiff School of Biosciences, Cardiff University, Biomedical Sciences Building, Museum Avenue, Cardiff CF10 3 US, UK
}

\begin{abstract}
The transwell chamber migration assay and CCD digital camera imaging techniques were used to investigate the relationship between regulatory volume decrease (RVD) and cell migration in nasopharyngeal carcinoma cells (CNE-2Z cells). Both migrated and non-migrated CNE-2Z cells, when swollen by $47 \%$ hypotonic solution, exhibited RVD which was inhibited by extracellular application of chloride channel blockers adenosine 5'-triphosphate (ATP), 5-nitro-2-(3phenylpropylamino) benzoic acid (NPPB) and tamoxifen. However, RVD rate in migrated CNE-2Z cells was bigger than that of non-migrated cells and the sensitivity of migrated cells to NPPB and tamoxifen was higher than that of nonmigrated cells. ATP, NPPB and tamoxifen also inhibited migration of CNE- $2 Z$ cells. The inhibition of migration was positively correlated to the blockage of RVD, with a correlation coefficient $(r)=0.99$, suggesting a functional relationship between RVD and cell migration. We conclude that RVD is involved in cell migration and RVD may play an important role in migratory process in CNE-2Z cells.
\end{abstract}

Keywords: tumor cells, chloride channel blockers, cell volume, cell migration, transwell chamber.

\section{INTRODUCTION}

Tumor cell migration is one of the crucial steps in the metastatic cascade. Cell migration is accompanied by changes in shape and volume of cells that are thought to be involved in the cells' ability to move through the narrow space [1] and is accompanied by cytoskeletal reorganization, morphological polarization and membrane ruffling $[2,3]$.

Two distinct phenomena, regulatory volume decrease (RVD) and regulatory volume increase (RVI), contribute to the controls of cell volume by different mechanisms [4]. RVD is mainly achieved by the activation of separate volume-regulated $\mathrm{K}^{+}$and $\mathrm{Cl}^{-}$channels in many cell types [5]. It has been reported that $\mathrm{K}^{+}$and $\mathrm{Cl}^{-}$channels are involved in cell migration, although the exact roles of $\mathrm{K}^{+}$ and $\mathrm{Cl}^{-}$channels in the cell migration is not clear [6]. For example, spreading of granulocytes, a process related to

\footnotetext{
*Correspondence: Li Xin CHEN

Tel: +44-29-20874088;

E-mail: CHENL1@cardiff. ac.uk
}

migration, depends on $\mathrm{Cl}^{-}$efflux [7]; Locomotion of transformed renal epithelial (MDCK-F) cells is regulated by the activity of $\mathrm{K}^{+}$and $\mathrm{Cl}^{-}$channels [8]; Volume-activated $\mathrm{Cl}^{-}$ current contributes to cell shape and volume changes required for glioma cell migration through brain tissue [9, 10]. Moreover, our previous study also indicate that the volume-activated $\mathrm{Cl}^{-}$current is involved in migration of nasopharyngeal carcinoma (CNE-2Z) cells [11].

The aim of this work was to study the role of RVD in CNE-2Z cells migration. Our results suggest that RVD is required for the $\mathrm{CNE}-2 \mathrm{Z}$ cells migration.

\section{MATERALS AND METHODS}

\section{Cell preparation}

The poorly differentiated nasophyaryngeal carcinoma cells (CNE2Z) were prepared by a method described previously [12]. CNE-2Z cells were grown in culture medium (RPMI 1640 with $10 \%$ new-born calf serum, $100 \mathrm{IU} / \mathrm{ml}$ penicillin, and $100 \mu \mathrm{g} / \mathrm{ml}$ streptomycin) at $37^{\circ} \mathrm{C}$ in a humidified atmosphere of $5 \% \mathrm{CO}_{2}$ and were subcultured every other day.

\section{Cell migration}

The migration ability of CNE- $2 \mathrm{Z}$ cells was assessed by an in vitro 
model, transwell migration assay [11]. Cells $\left(3 \times 10^{5}\right)$ were plated on top of a culture insert with $12 \mu \mathrm{m}$ pores (Costar Corporation, Cambridge, MA), which was situated in a well of a 24-well culture plate and immersed in the culture medium. The bottom side of the insert was covered with $10 \mu \mathrm{l}$ of fibronectin $(0.5 \mathrm{mg} / \mathrm{ml})$ before experiments. The cells were incubated at $37^{\circ} \mathrm{C}$ for $6 \mathrm{~h}$. The cells on the upper surface of the insert were then removed using cotton swabs and those on the bottom side, the migrated cells, were collected by trypsinizing and resuspended in culture medium. The number of migrated cells was obtained by cell counting using hemocytometers.

The percentage of migrated cells (migration rate) was calculated by dividing the total seeded cells $\left(3 \times 10^{5}\right)$ with migrated cells. The degree of inhibition of cell migration by inhibitors was calculated by the equation:

Inhibition of migration $(\%)=\left(\mathrm{Mig}_{\mathrm{ctrl}}-\mathrm{Mig}_{\mathrm{t}}\right) / \mathrm{Mig}_{\mathrm{ctrl}} \times 100 \%$,

which $\mathrm{Mig}_{\mathrm{ctrl}}$ is the migration rate of control cells, $\mathrm{Mig}_{\mathrm{t}}$ is the migration rate of treated cells.

\section{Measurements of cell volume and RVD}

Cell volume and RVD rate were measured using the methods described by us previously $[13,14]$. Cell suspension of control cells was obtained by trypsinizing cultured cells in a flask and resuspending them in culture medium. Migrated cells were collected by the tripsinizing method described above (see Cell migration in Methods). Control cells or migrated cells was plated onto round coverslips with 22-mm diameter and incubated for about 1-2 h. The coverslips containing cells were then stuck to the base of a perfusion chamber and mounted onto an inverted microscope (Olympus, Japan). The bath volume was $0.5 \mathrm{ml}$. Solutions were supplied and exchanged by a continuous perfusion system with an inflow rate of $4 \mathrm{ml} / \mathrm{min}$. All experiments were carried out at room temperature $\left(20-24^{\circ} \mathrm{C}\right)$. Cell images were captured by a CCD digital camera (4910, Cohu Inc., USA) that was connected to the microscope. During the RVD experiments, cell images were taken every $60 \mathrm{~s}$. The acquisition of cell images was controlled by the Scion image processor and analysis software (Scion Corporation, USA). RVD experiments were performed using the following protocols: cells were bathed in an isotonic solution for $10 \mathrm{~min}$ (only 5 images of the last $5 \mathrm{~min}$ were taken), in a hypotonic solution (or a hypotonic solution with $\mathrm{Cl}^{-}$ channel blockers) for $20 \mathrm{~min}$ and then in isotonic conditions for 5 min. The cell images were analyzed by the computer software and RVD levels were calculated. Cell volume was computed from cell diameter. The level of regulatory volume decrease (RVD) was calculated using the equation:

$\operatorname{RVD}(\%)=\left(\mathrm{V}_{\max }-\mathrm{V}_{\min }\right) /\left(\mathrm{V}_{\max }-\mathrm{V}_{0}\right) \times 100 \%$,

which $\mathrm{V}_{0}$ is the cell volume in isotonic solution before hypotonic shock, $\mathrm{V}_{\max }$ the peak volume in hypotonic solutions and $\mathrm{V}_{\min }$ the volume before returning to isotonic solution.

The percentage of block of RVD by inhibitors was calculated using the equation, inhibition of RVD $(\%)=\left(R^{2} D_{\text {ctrl }}-R D_{t}\right) /$ $\mathrm{RVD}_{\text {ctrl }} \times 100 \%$, which $\mathrm{RVD}_{\text {ctrl }}$ is the RVD in control cells, $\mathrm{RVD}_{\mathrm{t}}$ is the RVD of cells treated with inhibitors.

\section{Solutions and chemicals}

The isotonic bath solution contained (mM): $70 \mathrm{NaCl}, 0.5 \mathrm{MgCl}_{2}$, $2 \mathrm{CaCl}_{2}, 10$ HEPES, and 140 D-mannitol. The osmolarity was measured by depression of the freezing point using an osmometer (Osmomat 30, Gonotec, Berlin, Germany). The isotonic solution
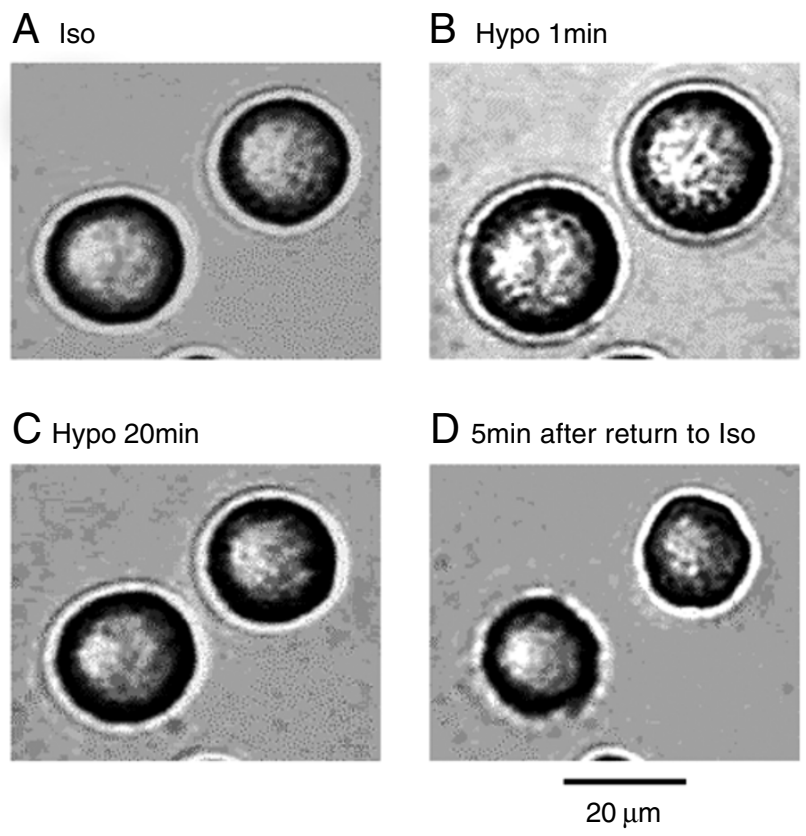

Fig. 1 Cell images in $47 \%$ hypotonic challenges. Phase-contrast images showed the response of CNE-2Z cells to a hypotonic solution. Perfusion of the cells with $47 \%$ hypotonic solution swelled the cells (B, Hypo $1 \mathrm{~min}$ ). Cell swelling induced an incomplete regulatory volume decrease (C, Hypo $20 \mathrm{~min}$ ). On returning to isotonic conditions, cell volume decreased below its control value (D). Iso, cells in isotonic condition (A). Hypo 1, or Hypo 20: cell images acquired at $1 \mathrm{~min}$ or $20 \mathrm{~min}$ after bathing in $47 \%$ hypotonic solution.

was adjusted to $300 \mathrm{mOsM}$ with D-mannitol. The hypotonic bath solution was obtained by omitting $140 \mathrm{mM}$ of D-mannitol from the solution, giving an osmolarity of $160 \mathrm{mOsM}$ (47\% hypotonicity). The $\mathrm{pH}$ of the bath solutions was adjusted to 7.4 with Tris base. The buffer used to wash cells contained (mM): $125 \mathrm{NaCl}, 5 \mathrm{KCl}, 10$ $\mathrm{NaHCO}_{3}, 10$ HEPES, 5 glucose, 20 sucrose and was adjusted to $\mathrm{pH}$ 7.4. Stock solutions of $100 \mathrm{mM}$ Adenosine Triphosphate (ATP), $100 \mathrm{mM}$ 5-nitro-2-(3-phenylpropylamino)benzoic Acid (NPPB) and $50 \mathrm{mM}$ tamoxifen were prepared, respectively, by distilled water, DMSO or methanol. All chemicals were purchased from Sigma.

\section{Statistics}

Values were expressed as mean \pm S.D. (number of observations). ANOVA was used to test for significant differences and $P<0.05$ was taken to be significant. All experiments were repeated at least four times.

\section{RESULTS}

\section{Up-regulation of $R V D$ capacity in migrated CNE-2Z cells}

Migrated and non-migrated cells were harvested, resuspended in normal culture medium, plated onto glass coverslips and incubated for 1-2 h. RVD experiments were 


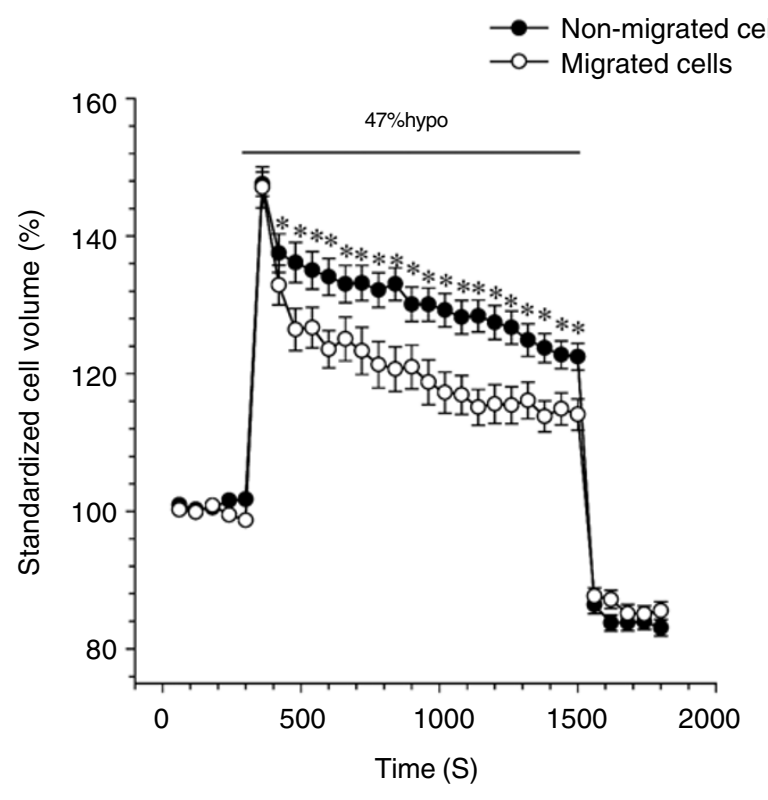

Fig. 2 Regulatory volume decrease (RVD) in migrated and nonmigrated CNE-2Z cells. The figure shows the time courses of responses of migrated and non-migrated cells to $47 \%$ hypotonic stimulus ( 21 and 22 cells, respectively, in four experiments). The hypotonic solution swelled the cells and induced an RVD when still bathed in the hypotonic solution. RVD level was higher in migrated cells than in non-migrated cells. Data in the figure represents the mean $\pm \mathrm{S}$. D. *, $P<0.01$ (vs migrated cells).

then performed. Under the experiment conditions, cells were round (Fig. 1). Cell volume was computed from cell diameter.

Both migrated and non-migrated cells exhibited a similar style of responses in RVD experiments. Cell size was stable when cells were bathed in isotonic condition. Exposing cells to $47 \%$ hypotonic solution swelled the cells. Cell swelling appeared in 30-60 $s$ and reached a peak in 1$2 \mathrm{~min}$. Cell volume increased by $47.6 \pm 1.8 \%$ in non-migrated cells ( 22 cells in 4 experiments, $P<0.01)$ and by $47.1 \pm 3.0 \%$ in migrated cells ( 21 cells in 4 experiments, $P<0.01)$. There was no significant difference between the two groups in swelling $(P>0.05)$. After the peak of swelling, each cell showed a subsequent RVD response. Cell volume decreased gradually although cells were still bathed in hypotonic solution, but cells could not regain completely their initial size. When the bath was returned to the isotonic condition, cells shrank before they regained the control size in both groups. Fig. 1 showed the responses of non-migrated CNE-2Z cells during a $47 \%$ hypotonic challenge.

As shown above, migrated and non-migrated cells responded to the hypotonic stimulation in a similar style.
The degree of cell swelling was not significantly different between the two groups. However, the rate of cell volume regulation was differentiated. The RVD rate in migrated cells was higher than that in non-migrated cells (Fig. 2). In migrated cells, the standardized cell volume decreased from $147.1 \pm 3.0 \%$ on the swelling peak to $114.1 \pm 2.3 \%$ in 20 min although still bathed in the hypotonic solution $(\mathrm{n}=21, P<0.01)$. Cell volume recovered by $70.9 \pm 4.2 \%$, which was significantly different to that in non-migrated cells $(P<0.05)$. The volume of non-migrated cells recovered only by $52.8 \pm 5.6 \%$ (from the standardized volume of $147.6 \pm 1.8 \%$ on swelling peak to $122.5 \pm 1.9 \%$ in 20 $\min , \mathrm{n}=22, P<0.01)$.

\section{Susceptiveness of migrated $\mathrm{CNE}-2 \mathrm{Z}$ cells to $\mathrm{Cl}^{-}$chan- nel blockers}

As shown above, RVD capacity was up-regulated in migrated CNE-2Z cells. Our previous study demonstrated that $\mathrm{Cl}^{-}$outflow via volume-sensitive chloride channels was one of the key mechanisms of RVD in CNE-2Z cells [15]. Would the susceptiveness of migrated CNE-2Z cells to $\mathrm{Cl}^{-}$ channel blockers also be modifided?

The results demonstrate that extracellular application $\mathrm{Cl}^{-}$channel blockers ATP, NPPB and tamoxifen inhibited RVD in both migrated and non-migrated CNE-2Z cells (Fig. 3). ATP in the final concentration of $10 \mathrm{mM}$ inhibited RVD by $95.9 \pm 7.7 \%$ ( 20 cells in 5 experiments) in migrated cells, which was not significantly different from that of $91.2 \pm 2.5 \%$ (15 cells in 5 experiments $)$ in non-migrated cells $(P>0.05)$. However the inhibitory effects of NPPB and tamoxifen were different between the migrated and non-migrated cells. NPPB $(100 \mu \mathrm{M})$ and tamoxifen $(20$ $\mu \mathrm{M})$ inhibited respectively the RVD by $91.2 \pm 1.9 \%(22$ cells in 5 experiments, $P<0.01)$ and $98.2 \pm 6.5 \%(20$ cells in 5 experiments, $P<0.01)$ in migrated cells, but only by $60.1 \pm 3.1 \%$ ( 20 cells in 5 experiments, $P<0.01$ ) and $61.2 \pm 2.1 \%$ ( 29 cells in 8 experiments, $P<0.01$ ) in non-migrated cells. The results indicated that the inhibitory effects of NPPB and tamoxifen were stronger on migrated cells than those on non-migrated cells $(P<0$. 01).

In the experiments, DMSO and methanol were used to prepare NPPB and tamoxifen solutions respectively. The final concentrations of them in experiments were $0.1 \%$ and $0.04 \%$. The effects of these chemicals on RVD were tested. The results showed that $0.1 \%$ DMSO or $0.1 \%$ methanol in these concentrations did not significantly alter the RVD.

\section{Inhibition of $\mathrm{CNE}-2 \mathrm{Z}$ cell migration by $\mathrm{Cl}^{-}$channel blockers}

The results of transwell migration assay demonstrated 
A

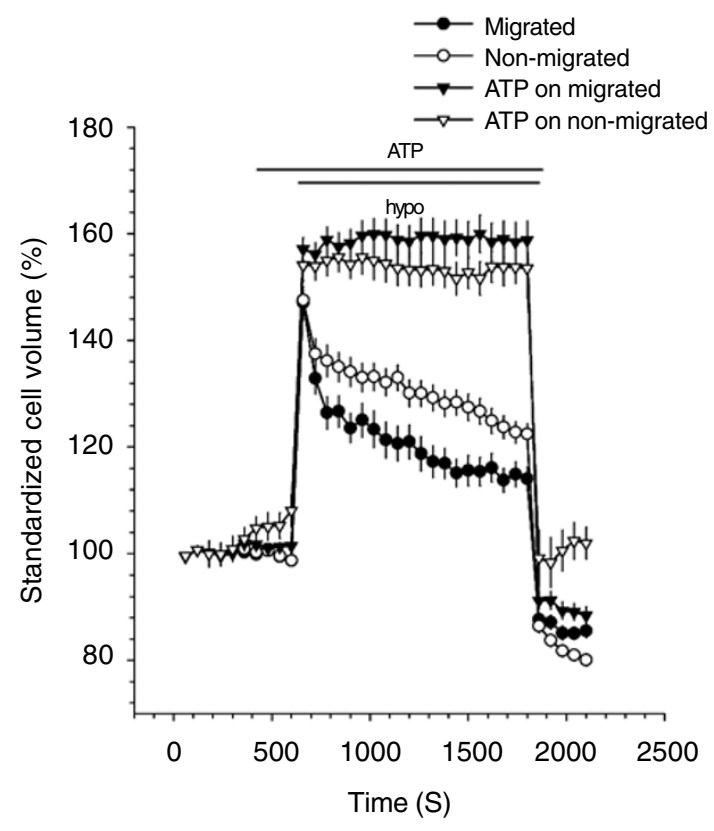

C

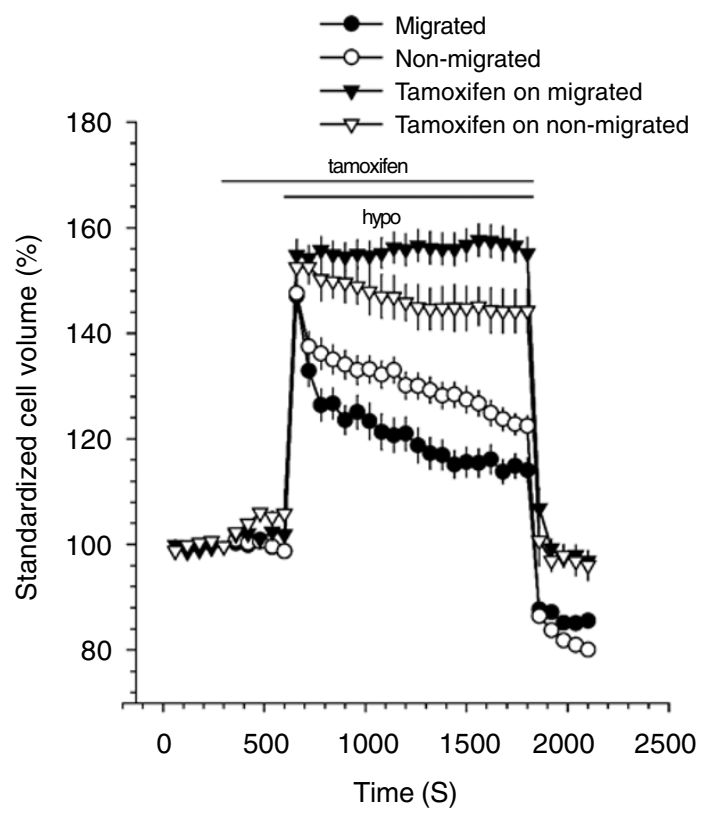

B

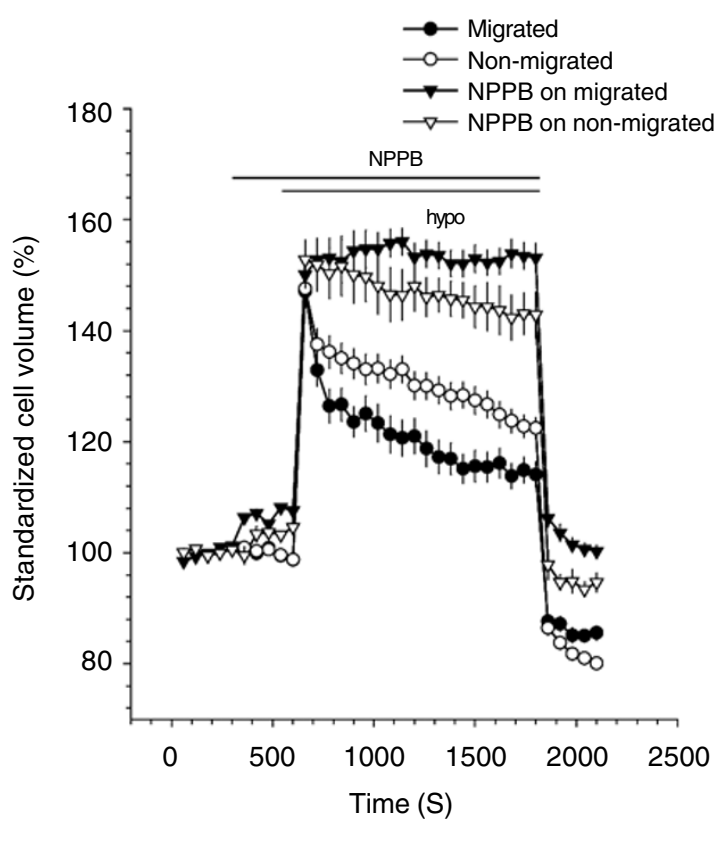

D

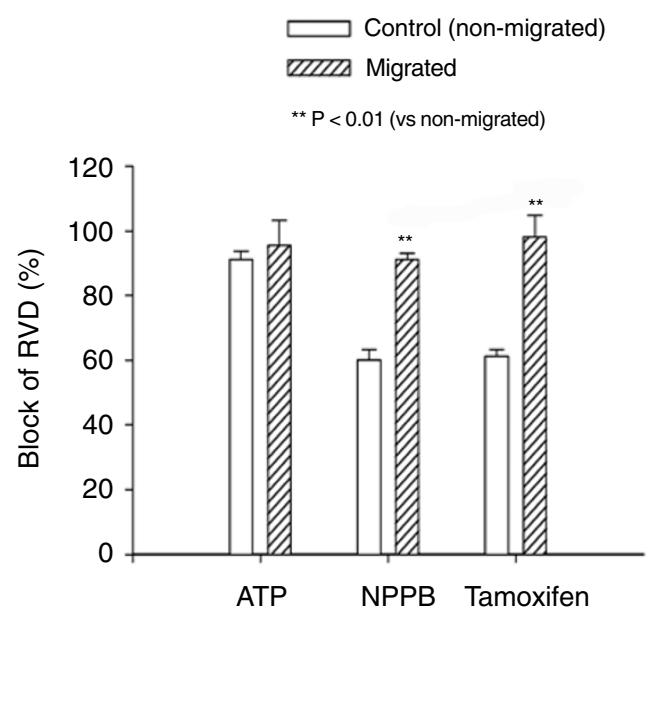

Fig. 3 Effects of $\mathrm{Cl}^{-}$channel blockers on RVD in migrated and non-migrated CNE-2Z cells. A 47\% hypotonic solution activated RVD in migrated cells and non-migrated cells (indicated by migrated and non-migrated, copied from Fig. 2). In both groups, the RVD was inhibited by extracellular application of $\mathrm{Cl}^{-}$channel blockers ATP $(\mathbf{A}, 10 \mathrm{mM})$, NPPB $(\mathbf{B}, 100 \mu \mathrm{M})$, or tamoxifen $(\mathbf{C}, 20 \mu \mathrm{M})$. NPPB and tamoxifen are less effective in non-migrated cells than in migrated cells. (D) The blockers were added to the bath solutions 5 min before and during the hypotonic shocks (showed by the bar). Data in the figure represents the mean \pm S.D.

that CNE-2Z cells possessed the ability to migrate across the pored filter membrane. $11.7 \pm 1.6 \%$ (5 experiments) of seeded cells migrated to the bottom side of the filter membrane in $6 \mathrm{~h}$. However in the presence of $\mathrm{Cl}^{-}$channel blockers, tamoxifen, NPPB or ATP, cell migration was significantly inhibited. Fig. 4 showed representative fields of CNE-2Z cells that successfully migrated across the chamber filters in the presence (Fig. 4C) or absence (Fig. 4B) 
Tab. 1 Effects of $\mathrm{Cl}^{-}$channel blockers on CNE-2Z cell migration

\begin{tabular}{lcccc}
\hline Group & Number $(\mathrm{n})$ & Concentration & Migration (\%) & Inhibition (\%) \\
\hline Control & 5 & & $11.67 \pm 1.64$ & \\
ATP & 5 & $1000 \mu \mathrm{M}$ & $8.47 \pm 1.58^{*}$ & $27.48 \pm 3.69$ \\
NPPB & 5 & $100 \mu \mathrm{M}$ & $8.31 \pm 1.09^{*}$ & $28.81 \pm 3.71$ \\
Tamoxifen & 5 & $20 \mu \mathrm{M}$ & $6.79 \pm 0.83^{* *}$ & $43.20 \pm 2.47$ \\
DMSO & 5 & $0.1 \%$ & $11.64 \pm 1.52$ & $-0.85 \pm 0.14$ \\
Methanol & 5 & $0.1 \%$ & $11.8 \pm 2.11$ & $1.53 \pm 0.15$ \\
\hline
\end{tabular}

Data are mean \pm S.D. $* P<0.05, * * P<0.01$ (vs control).

A

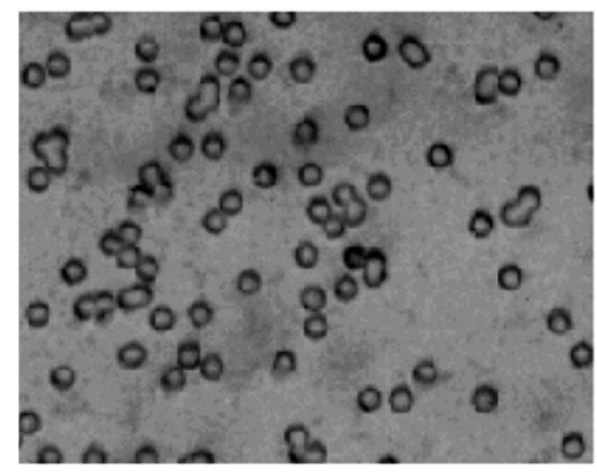

C

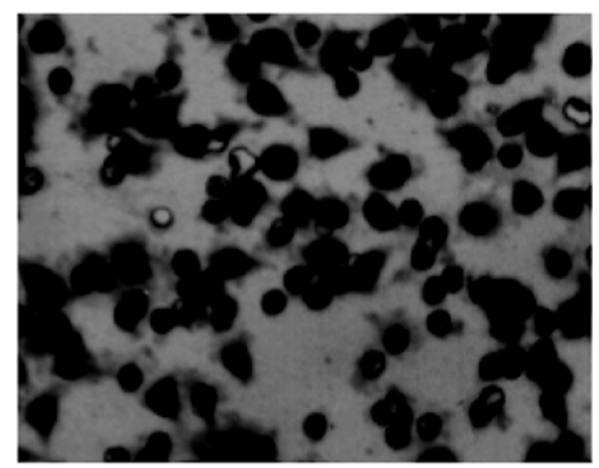

$\mathrm{B}$

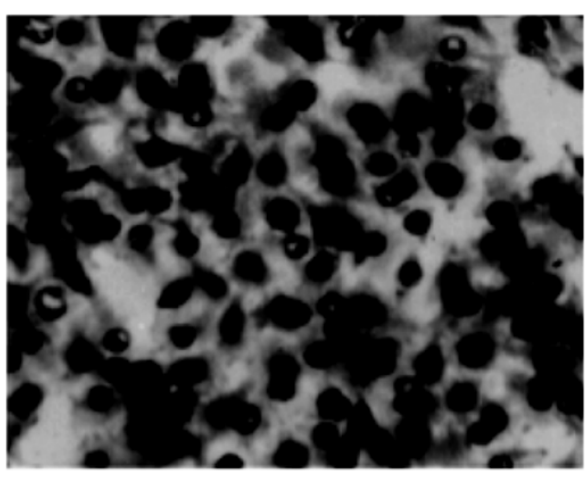

D

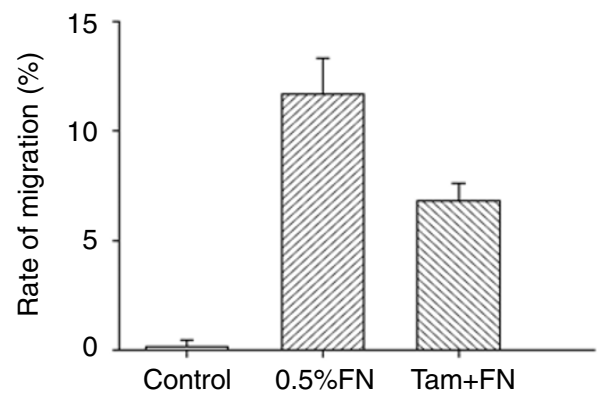

Fig. 4 Inhibitory effects of $\mathrm{Cl}^{-}$channel blockers on CNE-2Z cell migration. Figures show the migrated cells on the bottom side of the polycarbonate membranes stained with hematoxylin and eosin. They were observed by light microscopy at a magnification of $\times 100$ and captured by the CCD digital camera. A-C, photomicrographs of the bottom side of filters without attractant fibronectin (FN) (A), with fibronectin (B), and with fibronectin plus $20 \mu \mathrm{M}$ tamoxifen (C). D is the quantitated summary of the experiment illustrated in A-C. A shows the pores of the filter membrane without migrated cells.

of $20 \mu \mathrm{M}$ tamoxifen. Migration of CNE-2Z cells was reduced in the presence of tamoxifen. In Fig. 4B and 4C, attractant fibronectin was presented on the bottom side of the filter membranes. In the absence of fibronectin (Fig. $4 \mathrm{~A}$ ), cells did not migrate or only a few cells migrated through the pores. Fig. 4A showed the pores of the filter membrane without migrated cells.
The quantitative effects of $\mathrm{Cl}^{-}$channel blockers NPPB, ATP and tamoxifen on migration of CNE-2Z cells were shown in Tab. 1. All three blockers, which had been shown to suppress RVD process of CNE-2Z cells, exhibited inhibitory effects on $\mathrm{CNE}-2 \mathrm{Z}$ cell migration. The inhibition by $20 \mu \mathrm{M}$ tamoxifen $(43.20 \pm 2.47 \%, \mathrm{n}=5)$ was stronger than that by $100 \mu \mathrm{M}$ NPPB $(28.81 \pm 3.71 \%, \mathrm{n}=5)$ and 
A

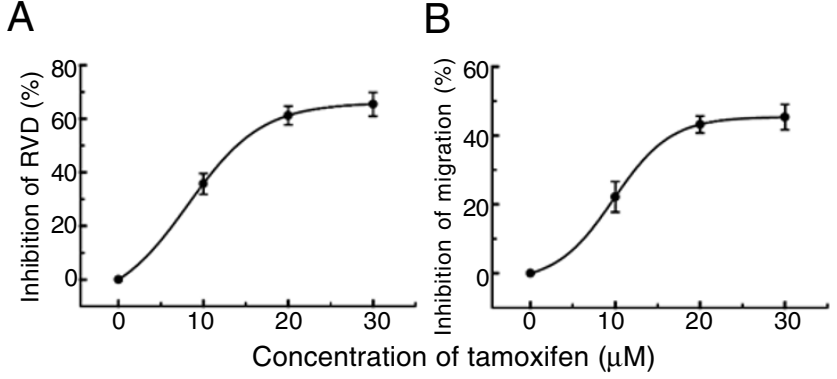

C

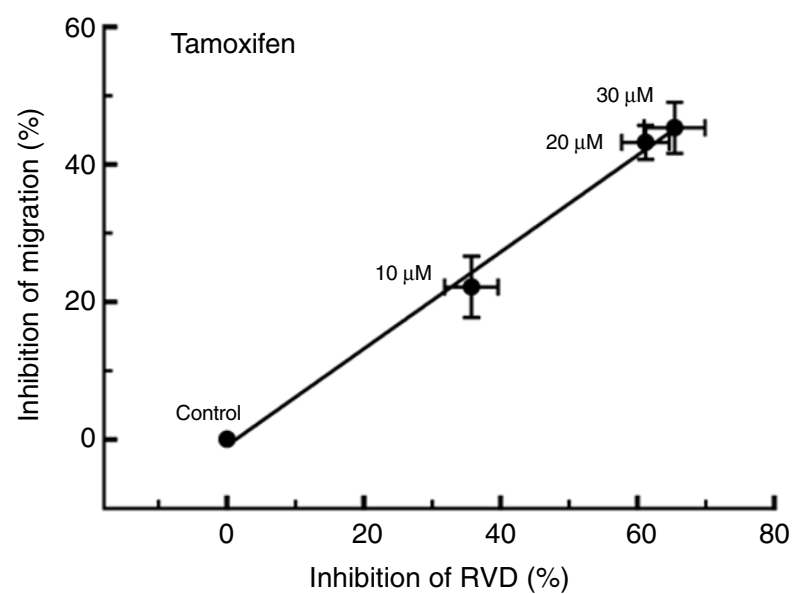

D

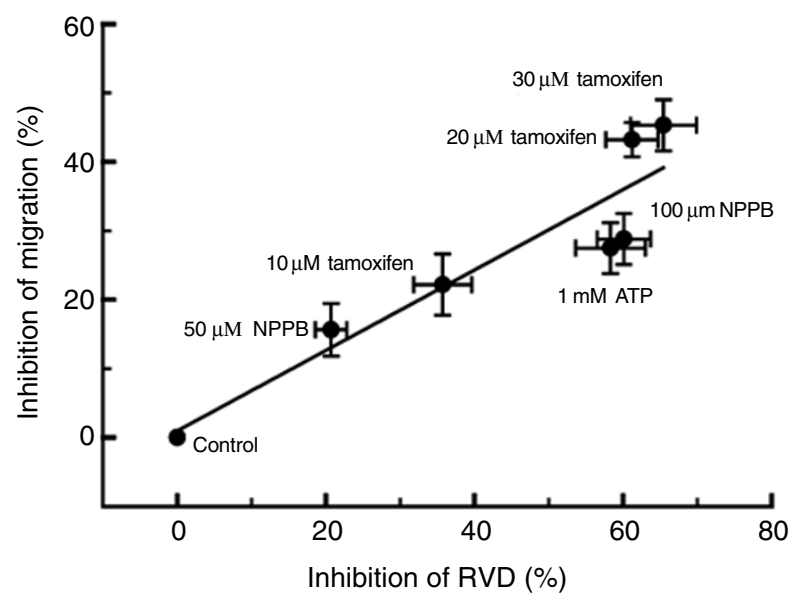

Fig. 5 Correlation between CNE-2Z cell migration and RVD. (A, B) present dose-dependent inhibitions of RVD and migration by tamoxifen. Plotting of the inhibition of cell migration against the inhibition of RVD by various concentrations of tamoxifen (C) or by different blockers (D) indicated that the inhibition of RVD was positively correlated to the inhibition of migration. The lines in $\mathbf{C}$ and $\mathbf{D}$ were obtained by fitting the data with a linear equation. Data are mean \pm S.D. of at least three experiments for each group.

$1 \mathrm{mM}$ ATP $(27.48 \pm 3.69 \%, \mathrm{n}=5)$. Because of the toxicity of ATP in high concentration (10 mM of ATP decreased significantly cell viability), the effect of $10 \mathrm{mM}$ ATP on cell migration rate was not tested.
In the experiments, the effects DMSO and methanol, which were used to prepare NPPB and tamoxifen solutions were evaluated. Treatment of cells with $0.1 \%$ DMSO or $0.1 \%$ methanol did not significantly affect cell migration. Moreover, neither of them in the indicated concentrations showed any cellular toxicity in the period of $6 \mathrm{~h}$.

\section{Correlation between RVD and cells migration dem- onstrated by chloride channel blockers}

As shown above, the RVD rate of migrated CNE-2Z cells was larger than that of non-migrated cells. Chloride channel blockers ATP, NPPB and tamoxifen inhibited cell migration as well as RVD. To analyze the relationship between the RVD and cell migration, the effects of chloride channel blockers on RVD and on cell migration were studied further.

Fig. 5A and 5B showed that both RVD and migration of CNE-2Z cells were inhibited by tamoxifen in a dose-dependent manner. Plotting of the inhibition of cell migration against the inhibition of RVD indicated that the inhibition of RVD was positively related to the inhibition of migration (Fig. 5C). The correlation coefficient ( $r$ ), obtained by fitting the data in the figure with a linear equation $\mathrm{y}=\mathrm{y}_{0}+$ ax, was $0.99(P<0.01)$.

Analysis of all the data obtained (1 mM ATP; 50 and $100 \mu \mathrm{M}$ NPPB; 10, 20 and $30 \mu \mathrm{M}$ tamoxifen) also indicated a linear correlation between the inhibition of RVD and that of cell migration, with a correlation coefficient of $0.93(P<0.01)$ (Fig. 5D).

\section{DISCUSSION}

\section{RVD and cell migration}

This study demonstrated that RVD rate was higher in migrated cells than in non-migrated cells. The data implicate that RVD process is involved in cell migration. Our previous studies demonstrated that $\mathrm{Cl}^{-}$outflow through volume-activated chloride channels was one of the key factors involved in RVD in nasopharyngeal carcinoma cells (CNE-2Z cells) [15]. In this study, we showed that chloride channel blockers inhibited cell migration as well as RVD in CNE-2Z cells. The inhibition of cell migration was positively related to the suppression of RVD in CNE-2Z cells. The results suggest that RVD process is involved in cell migration in CNE-2Z. How is RVD involved in cell migration?

It is known that cells must change their shape during migration, especially when migrating through narrow pores. A migrating cell is typically polarized when the cell is crawling over a two-dimensional surface. The front is formed by a flat, organelle-free, fan-like process, the so-called lamellipodium. The rear end is formed by the prominent cell body that extends into a uropod [6]. 
It is proposed that salt and osmotically obliged water uptake mediated by the parallel operation of $\mathrm{Na}^{+} / \mathrm{H}^{+}$and $\mathrm{Cl}^{-} / \mathrm{HCO}_{3}{ }^{-}$exchange as well as $\mathrm{Na}^{+}-\mathrm{HCO}_{3}{ }^{-}$cotransport at the front of migrating cells contribute to the extension of the lamellipodium $[4,16,17]$. Increasing volume and membrane tension eventually trigger massive ion efflux, resulting in a local shrinkage of the rear part. The shrinkage of the rear part is similar to the process of regulatory volume decrease in a cell. Thus, RVD may be involved in cell migration via the RVD process happening in the rear part of cells. It has been reported that the distribution of ion channels and transporters is polarized in migrating cells [4].

RVD may also affect cell migration by controlling cell volume. It has been shown that cell volume changes is associated with cell migration [18]. Among others, cytoskeleton may be an important factor to associate cell volume with migration. Cytoskeleton is important for cell migration as well as for cell volume regulation. Cell volume regulation and the cytoskeleton are closely interrelated with each other. Cell volume regulation depends on an intact actin cytoskeleton [19], and perturbations of cell volume themselves change the polymerisation of actin filaments. Cell swelling is accompanied by a disintegration of actin filaments, and cell shrinkage is followed by an assembly of actin filaments [20,21]. Cell migration - a process in which a complex and co-ordinated turnover of actin filaments is of central importance [2, 22, 23] - also relies on cell volume homeostasis. The interdependence of actin filaments and cell volume indicates the importance of cell volume regulation in cell migration.

\section{Chloride channels and cell migration}

Our results showed that not only the rate of RVD in migrated CNE-2Z cells was up-regulated, but also the sensitivity of RVD to chloride channel blockers was changed. The inhibition of RVD by chloride channel blockers, NPPB and tamoxifen, was stronger in migrated CNE-2Z cells than in non-migrated cells. This indicates that the mechanisms underlying RVD were modulated during the process of CNE-2Z cell migration or in migrated cells. This modulation may facilitate cell migration.

Our previous studies demonstrated that the functional expression of volume-activated chloride channels was upregulated in migrated CNE-2Z cells and the properties of the volume-activated chloride current and the sensitivity of the current to $\mathrm{Cl}^{-}$channel blockers were changed [11]. The inhibition of NPPB and tamoxifen on the current was stronger in migrated cells than in non-migrated cells. These changes were coincident with the changes of RVD in this study. These suggest that modulation of volume-activated chloride channels or their expression is one of the key mechanisms underlying RVD change in migration and this change was required for $\mathrm{CNE}-2 \mathrm{Z}$ cell migration.

The main mechanisms underlying RVD in many cells are the activation of $\mathrm{K}^{+}$channels and chloride channels, followed by the osmotic outflow of water. It has been reported that $\mathrm{K}^{+}$channels play important roles in cell migration $[6,24,25,26]$ and are functionally and structurally polarized distributed in the rear part of migrating cells and this polarization facilitates cell migration [6]. In CNE$2 \mathrm{Z}$ cells, activation of $\mathrm{Cl}^{-}$channels is one of the key factors for RVD process [12]. Block of $\mathrm{Cl}^{-}$channels inhibits RVD and cell migration. Whether volume-activated chloride channels bear the polarizing property to facilitate cell migration is not clear.

\section{ACKNOWLEDGEMENTS}

This work was supported by grants from the Wellcome Trust UK (056909/299/Z), Ministry of Education of China (GJ9901), the Health Department of Guangdong Province (A2001474) and Guangdong Medical College Fund for Young Scholars (XQ0306).

\section{Received, Nov 2, 2004}

Revised, Mar 22, 2005

Accepted, Apr 1, 2005

\section{REFERENCES}

1 Fridman R, Scott AF, Muller D, Reich R, Penno MB. The role of cell adhesion and migration in the in vitro invasiveness of mouse adrenal carcinoma cells. Invasion Metastasis 1990; 10:208-24.

2 Lauffenburger DA, Horwitz AF. Cell migration: a physically integrated molecular process. Cell 1996; 84:359-69.

3 Schwab A. Ion channels and transporters on the Move. News Physiol Sci 2001; 16:29-33.

4 Lang F, Busch GL, Ritter M, et al. Functional significance of cell volume regulatory mechanisms. Physiol Rev 1998; 78:247-306.

5 Waldegger S, Steuer S, Risler T, et al. Mechanisms and clinical significance of cell volume regulation. Neprol Dial Transplant 1998; 13:867-74.

6 Schwab A. Function and spatial distribution of ion channels and transporters in cell migration. Am J Physiol Renal Physiol 2001; 280:F739-47.

7 Menegazzi R, Busetto S, Decleva E, et al. Triggering of chloride ion efflux from human neutrophils as a novel function of leukocyte $\beta_{2}$ integrins: relationship with spreading and activation of the respiratory burst. J Immunol 1999; 162:423-34.

8 Schwab A, Wojnowski L, Gabriel K, Oberleithner H. Oscillating activity of a $\mathrm{Ca}^{2+}$-sensitive $\mathrm{K}^{+}$channel—a prerequisite for migration of alkali-transformed Madin-Darby canine kidney (MDCKF) cells. J Clin Invest 1994; 93:1631-6.

9 Soroceanu L, Manning TJ, Sontheimer H. Modulation of glioma cell migration and invasion using $\mathrm{Cl}^{-}$and $\mathrm{K}^{+}$ion channel blockers. J Neurosci 1999; 19:5942-54.

10 Ransom CB, O'Neal JT, Sontheimer H. Volume-activated chloride currents contribute to the resting conductance and invasive 
migration of human glioma cells. J Neurosci 2001; 21:7674-83.

11 Mao JW, Chen LX, Sun XR, et al. Volume-activated Cl- current in migrated nasopharyngeal carcinoma cells. Sheng Li Xue Bao 2004; 56:525-30.

12 Chen L, Wang L, Zhu L, et al. Cell cycle-dependent expression of volume-activated chloride currents in nasopharyngeal carcinoma cells. Am J Physiol Cell Physiol 2002; 283:C1313-1323.

13 Wang L, Chen L, Zhu L, et al. Regulatory volume decrease is actively modulated during the cell cycle. J Cell Physiol 2002; 193:110-9.

14 Walker VE, Stelling JW, Miley HE, Jacob TJ. Effect of coupling on volume regulatory response of ciliary epithelial cells suggests mechanism for secretion. Am J Physiol 1999; 276:C1432-8.

15 Chen LX, Wang LW, Zhu LY, et al. The role of $\mathrm{Cl}^{-}$in regulatory volume decrease of nasopharyngeal carcinoma cells. Zhongguo Bing Li Sheng Li Xue Za Zhi 2002; 18:490-3.

16 Klein M, Rossmann H, Seidler U, Schwab A. Cellular knockout of $\mathrm{Na}^{+} / \mathrm{H}^{+}$exchanger reveals a role for the $\mathrm{Na}^{+}-\mathrm{HCO}_{3}{ }^{-}$ cotransporter for cell migration. Pflugers Arch 2000; 439:R320.

17 Ritter M, Schratzberger P, Rossmann H, et al. Effect of inhibitors of $\mathrm{Na}^{+} / \mathrm{H}^{+}$exchange and gastric $\mathrm{H}^{+} / \mathrm{K}^{+}$ATPase on cell volume, intracellular $\mathrm{pH}$ and migration of human polymorphonuclear leucocytes. Br J Pharmacol 1998; 124:627-38.

18 Rosengren S, Henson PM, Worthen GS. Migration-associated volume changes in neutrophils facilitate the migratory process in vitro. Am J Physiol Cell Physiol 1994; 267:C1623-32.

19 Downey GP, Grinstein S, Sue-A-Quan A, Czaban B, Chan CK. Volume regulation in leukocytes: requirement for an intact cytoskeleton. J Cell Physiol 1995; 163:96-104.

20 Hallows KR, Packman CH, Knauf PA. Acute cell volume changes in anisotonic media affect F-actin content of HL-60 cells. Am J Physiol 1991; 261:C1154-61.

21 Schwab A, Reinhardt J, Seeger P, Reinhardt J, Dartsch PC. Migration of transformed renal epithelial cells is regulated by $\mathrm{K}^{+}$ channel modulation of actin cytoskeleton and cell volume. Pflugers Arch 1999; 438:330-7.

22 Condeelis J. Life at leading edge: the formation of cell protrusions. Annu Rev Cell Biol 1993; 9:411-44.

23 Mitchison TJ, Cramer LP. Actin-based cell motility and cell locomotion. 1996; 84:371-9.

24 Roll A, Wulf A, Schuricht B, Schwab A. K ${ }^{+}$channel (hIK1) dependent migraion of human neutrophil granulocytes. Pflugers Arch 2000; 439:R447.

25 Levite M, Cahalon L, Peretz A, et al. Extracellular $\mathrm{K}^{+}$and opening of voltage-gated potassium channels activate $\mathrm{T}$ cell migration and functional association between Kv1.3 channels and $\beta_{1}$ integrins. J Exp Med 2000; 191:1167-76.

26 Hendriks R, Morest DK, Kaczmared LK. Role in neuronal cell migration for high-threshold potassium currents in the chick hindbrain. J Neurosci Res 1999; 58:805-14. 